\title{
The prevalence of asthma and allergies in Singapore; data from two ISAAC surveys seven years apart
}

\author{
X S Wang, T N Tan, L P C Shek, S Y Chng, C P P Hia, N B H Ong, S Ma, B W Lee, D Y T Goh
}

Arch Dis Child 2004;89:423-426. doi: 10.1136/adc.2003.031112

See end of article for authors' affiliations

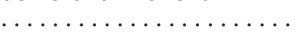

Correspondence to: A/Prof. D Y T Goh, Department of Paediatrics, National University of Singapore, National University Hospital, 5 Lower Kent Ridge Road, Singapore 119074. paegohył@nus.edu.sg

Accepted 26 August 2003

\begin{abstract}
Background and Aims: Over the past few decades, the prevalence of asthma has been increasing in the industrialised world. Despite the suggestion of a similar increase in Singapore, the 12 month prevalence of wheeze among schoolchildren in 1994 was 2.5 -fold less than that reported in western populations. It was hypothesised that with increasing affluence in Singapore, the asthma prevalence would further increase and approach Western figures. A second ISAAC survey was carried out seven years later to evaluate this hypothesis.

Methods: The cross-sectional data from two ISAAC questionnaire based surveys conducted in 1994 $(n=6238)$ and in $2001(n=9363)$ on two groups of schoolchildren aged 6-7 and 12-15 years were compared. The instruments used were identical and the procedures standardised in both surveys.

Results: Comparing data from both studies, the change in the prevalence of current wheeze occurred in opposing directions in both age groups-decreasing in the 6-7 year age group (16.6\% to $10.2 \%$ ) but increasing to a small extent in the $12-15$ year age group (9.9\% to $11.9 \%$ ). The 12 month prevalence of rhinitis did not change; there was an increase in the current eczema symptoms in both age groups.

Conclusion: The prevalence of current wheeze, a surrogate measure of asthma prevalence, has decreased significantly in the 6-7 year age group. Eczema was the only allergic disease that showed a modest increase in prevalence in both age groups.
\end{abstract}

l: recent decades, the increasing prevalence of childhood asthma and atopy has been supported by studies including objectively measured asthma related parameters. ${ }^{1-5}$ This increase has been observed in different age groups in different populations over the past several decades. It has been hypothesised that environmental rather than genetic causes were responsible for this and that with increasing westernisation, less developed communities would follow this trend. ${ }^{6}$ Recently, however, several studies in western populations have reported that this increase seems to have slowed down or plateaued,,$^{78}$ suggesting that the environmental influences that promote asthma have reached their maximum effect on a susceptible genetic background.

In the 1990s, the results of phase one of the ISAAC survey involving about half a million schoolchildren internationally showed wide ranging differences (up to 20-fold) in the 12 month prevalence of wheeze between communities (1.6$36.8 \%) .{ }^{9}$ Compared with data from around the world, the 12 month prevalence of asthma, rhinoconjunctivitis, and eczema in Singapore was around the middle of the range of reported values. In this study, we evaluated the changes in prevalence of symptoms of asthma and allergies by comparing the data from phase one and phase three of the ISAAC surveys conducted in Singapore seven years apart.

\section{METHODS}

\section{Design and subjects}

This study was a comparison of cross-sectional data from ISAAC written questionnaire surveys conducted in 1994 and 2001. The cluster sampling method was identical in both surveys: schools were sampled randomly from the lists of all primary and secondary schools in Singapore. Students in the sampled schools at the ages of interest (6-7 and $12-15$ years old) were all invited to complete the questionnaire.

\section{Questionnaire and data collection}

Standard ISAAC core questions for wheezing, rhinitis, and eczema were used. In both surveys, socioeconomic status of the respondents was assessed by including questions on type of residence (public or private housing), which was shown in our ISAAC phase one study to be a reliable indicator. ${ }^{10}$ In the 2001 survey, additional questions related to environmental factors were included in the questionnaire. The data from this additional section will not be presented in this paper.

The method of data collection, described in our previous paper, ${ }^{10}$ was identical between the two surveys. In brief, the questionnaires were completed by the parents for the 6-7 year age group, and by the students themselves in the 12-15 year age group. Both surveys were conducted over the same months of the year (March to November). Only one of the randomly selected primary schools in 1994, had its counterpart secondary school selected in the 2001 survey. Thus the likelihood of surveying the same children-6-7 years in 1994 and 12-15 years in 2001 was small (estimated at not more than 5\%-that is, 250 students-of the latter cohort).

\section{Data analysis}

In order to accommodate the cluster sampling survey design, the Survey Data Analysis software (SUDAAN 8.02, RTI, Research Triangle Park, NC) was used. Data were weighted for the selection probability of schools and the response probabilities, which were estimated using response rate at school level and at subject level. Design of sampling without replacement was chosen due to the large sampling fraction from all primary sampling units (PSU). Weighted logistic models were used for adjusting age, gender, race, and socioeconomic status (type of housing) in prevalence comparison between the two surveys. All analyses have taken a $p$ value of $<0.05$ to represent statistical significance.

Taking into account cluster sampling, the estimated design effect for "wheezing in the past year" was 1.14 based on our survey. At the outset of the survey, a sample size of about 3700 for each age group was estimated to be sufficient to detect an increase of $2 \%$ in the prevalence of asthma symptoms from 1994 with 95\% statistical power. A sample 
Table 1 Demographic and socioeconomic characteristics of the survey respondents

\begin{tabular}{|c|c|c|c|c|c|c|}
\hline & \multicolumn{3}{|c|}{ 6-7 year age group: $n(\%)$} & \multicolumn{3}{|c|}{$12-15$ year age group: $n(\%)$} \\
\hline & 1994 & 2001 & p value* & 1994 & 2001 & p value \\
\hline Total subjects surveyed & 2030 & 5305 & - & 4208 & 4058 & - \\
\hline Total schools sampled & 10 & 21 & - & 12 & 15 & - \\
\hline \multicolumn{7}{|l|}{ Sex } \\
\hline Female & 45.7 & 47.7 & & 43.5 & 57.8 & \\
\hline Male & 51.6 & 50.7 & 0.257 & 53.8 & 41.4 & $<0.001$ \\
\hline Not stated & 2.7 & 1.6 & & 2.7 & 0.8 & \\
\hline \multicolumn{7}{|l|}{ Race } \\
\hline Chinese & 83.5 & 69.9 & & 76.0 & 75.0 & \\
\hline Malay & 8.7 & 19.1 & & 14.1 & 12.3 & \\
\hline Indian & 3.1 & 7.8 & $<0.001$ & 5.0 & 8.2 & $<0.001$ \\
\hline Other/not stated & 4.7 & 3.2 & & 4.9 & 4.5 & \\
\hline \multicolumn{7}{|l|}{ Type of housing } \\
\hline Public housing & 59.5 & 86.0 & & 80.9 & 68.8 & \\
\hline Private condominium & 13.5 & 8.1 & & 7.6 & 15.3 & \\
\hline Landed property & 21.2 & 3.6 & $<0.001$ & 9.0 & 14.2 & $<0.001$ \\
\hline Not stated & 5.8 & 2.3 & & 2.5 & 1.7 & \\
\hline
\end{tabular}

size of 4000 for each age group was chosen. All analyses have taken a $\mathrm{p}$ value of $<0.05$ to represent statistical significance.

\section{RESULTS}

There were 6238 and 9363 responses in the surveys of $1994^{10}$ and 2001, respectively. The response rates were $90 \%$ in 1994 and $91 \%$ in 2001 . Table 1 shows the demographic characteristics of the respondents from two surveys. Due to the significant differences in demographic make up between the surveys and the influence of these factors on prevalence rates, statistical adjustment for these factors were made for comparative analyses.

Table 2 presents the prevalence rates of symptoms of asthma, rhinitis, and eczema for both studies and their comparison. A reduction in asthma symptom prevalence was seen in the 6-7 year age group, with a $6.4 \%$ decrease in 12 month wheeze. In the 12-15 year age group, there was however, a small $(2 \%)$ increase in 12 month wheeze (9.9$11.9 \%)$. Only the symptom of nocturnal cough showed a consistent significant increase in both age groups. Symptoms of rhinoconjunctivitis did not show significant change in either age group. Symptoms of eczema (chronic itchy rash with typical distribution) were significantly increased in both age groups.

When changes in the severity of symptoms of asthma, rhinitis, and eczema were examined (table 3), little change was observed for asthma and eczema symptoms, although there was a reduction in the number of wheeze episodes in the 6-7 year olds and wheeze limiting speech in 13-14 year olds. Rhinitis, however, showed a change towards increasing severity of symptoms in both age groups.

In terms of the prevalence of doctor diagnosed asthma, hay fever, and eczema, there was an increase for all three disorders (table 2), suggesting an improved awareness of these diseases in our population.

\section{DISCUSSION}

The increase of asthma and atopic disease prevalence around the world has been described as an epidemic. ${ }^{11}$ Data from the United States, ${ }^{12}$ Central America, ${ }^{13}$ Asia, ${ }^{14}$ and Europe ${ }^{15}{ }^{16}$ have shown increases up to and including the past decade. In Singapore, we reported an increase in cumulative asthma

Table 2 Positive response (\%) for each of the asthma, rhinitis, and eczema symptoms, with percentage change, in the overall population and different age groups for the 1994 and 2001 surveys

\begin{tabular}{|c|c|c|c|c|c|c|c|c|}
\hline & \multicolumn{4}{|c|}{ 6-7 year age group } & \multicolumn{4}{|c|}{$12-15$ year age group } \\
\hline & 1994 & 2001 & Change & $\mathrm{p}$ valuet & 1994 & 2001 & Change & $\mathrm{p}$ valuet \\
\hline \multicolumn{9}{|l|}{ Asthma } \\
\hline Ever wheezed & $28.6(1.0)$ & $21.5(0.6)$ & $-7.1(1.2)$ & 0.044 & $18.6(0.6)$ & $25.1(0.7)$ & $6.5(0.9)$ & $<0.001$ \\
\hline Wheeze in past year & $16.6(0.8)$ & $10.2(0.4)$ & $-6.4(0.9)$ & $<0.001$ & $9.9(0.5)$ & $11.9(0.5)$ & $2.0(0.7)$ & 0.015 \\
\hline Wheeze with exercise in past year & $8.4(0.6)$ & $4.4(0.3)$ & $-4.0(0.7)$ & $<0.001$ & $13.2(0.5)$ & $14.7(0.6)$ & $1.5(0.8)$ & 0.072 \\
\hline Nocturnal cough in past year & $14.9(0.8)$ & $19.5(0.6)$ & $4.6(1.0)$ & $<0.001$ & $11.4(0.5)$ & $21.2(0.7)$ & $9.7(0.8)$ & $<0.001$ \\
\hline Ever diagnosed asthma & $18.5(0.9)$ & $16.3(0.5)$ & $-2.2(1.0)$ & 0.464 & $20.7(0.6)$ & $27.4(0.7)$ & $6.7(0.9)$ & $<0.001$ \\
\hline \multicolumn{9}{|l|}{ Rhinitis } \\
\hline Ever had rhinitis & $30.8(1.0)$ & $29.3(0.6)$ & $-1.5(1.2)$ & 0.061 & $50.9(0.8)$ & $49.8(0.8)$ & $-1.2(1.1)$ & 0.707 \\
\hline Rhinitis in past year & $27.7(1.0)$ & $25.5(0.6)$ & $-2.2(1.2)$ & 0.194 & $41.8(0.8)$ & $42.1(0.8)$ & $0.3(1.1)$ & 0.401 \\
\hline Associated itchy eye in past year & $9.3(0.7)$ & $9.3(0.4)$ & $0.0(0.8)$ & 0.097 & $17.1(0.6)$ & $19.0(0.6)$ & $1.9(0.9)$ & 0.378 \\
\hline Ever diagnosed hay fever & $6.3(0.6)$ & $8.3(0.4)$ & $2.0(0.7)$ & 0.003 & $3.7(0.3)$ & $3.1(0.3)$ & $-0.6(0.4)$ & 0.207 \\
\hline \multicolumn{9}{|l|}{ Eczema } \\
\hline Chronic rash & $10.5(1.2)$ & $12.5(0.5)$ & $2.0(1.3)$ & 0.194 & $12.3(0.5)$ & $14.9(0.6)$ & $2.6(0.8)$ & 0.056 \\
\hline Chronic rash in past year & $8.9(1.1)$ & $11.0(0.4)$ & $2.1(1.2)$ & 0.155 & $9.5(0.5)$ & $11.6(0.5)$ & $2.1(0.7)$ & 0.034 \\
\hline Chronic rash with typical dist & $6.1(0.9)$ & $9.8(0.4)$ & $3.7(1.0)$ & 0.028 & $7.0(0.4)$ & $10.2(0.5)$ & $3.2(0.6)$ & $<0.001$ \\
\hline Ever diagnosed eczema & $3.0(0.7)$ & $8.8(0.4)$ & $5.8(0.8)$ & $<0.001$ & $4.1(0.3)$ & $5.8(0.4)$ & $1.7(0.5)$ & 0.810 \\
\hline
\end{tabular}




\begin{tabular}{|c|c|c|c|c|c|c|}
\hline & \multicolumn{3}{|c|}{ 6-7 year age group } & \multicolumn{3}{|c|}{$12-15$ year age group } \\
\hline & 1994 & 2001 & $\mathrm{p}$ valuet & 1994 & 2001 & $\mathrm{p}$ valuet \\
\hline $\begin{array}{l}\text { Wheeze in past year (n) } \\
\text { No. of wheezing episodes }\end{array}$ & 316 & 543 & & 407 & 472 & \\
\hline $1-3$ & 76.8 & 83.8 & & 78.6 & 77.7 & \\
\hline $4-12$ & 18.8 & 13.9 & & 14.8 & 15.5 & \\
\hline$>12$ & 4.4 & 2.3 & 0.008 & 6.6 & 6.8 & 0.468 \\
\hline \multicolumn{7}{|l|}{ Woken by wheeze } \\
\hline $\begin{array}{l}\text { Never } \\
<1 \text { per week }\end{array}$ & $\begin{array}{l}59.2 \\
30.4\end{array}$ & $\begin{array}{l}60.2 \\
30.5\end{array}$ & & $\begin{array}{l}58.7 \\
29.5\end{array}$ & $\begin{array}{l}60.9 \\
27.3\end{array}$ & \\
\hline$>1$ per week & 10.4 & 9.3 & 0.111 & 11.8 & 11.8 & 0.147 \\
\hline Wheezing attack limiting speech & 9.2 & 8.6 & 0.140 & 23.6 & 18.5 & 0.035 \\
\hline \multicolumn{7}{|l|}{ Interfering with daily activity } \\
\hline Not at all & 42.4 & 31.0 & & 35.8 & 23.2 & \\
\hline Little & 44.3 & 54.8 & & 50.5 & 57.4 & \\
\hline Moderate & 11.8 & 11.3 & & 9.9 & 15.1 & \\
\hline A lot & 1.5 & 2.9 & 0.003 & 3.8 & 4.3 & $<0.001$ \\
\hline Rash in past year (n) & 58 & 658 & & 394 & 472 & \\
\hline Persistent rash without clearing & 46.6 & 43.6 & 0.888 & 41.6 & 35.2 & 0.092 \\
\hline \multicolumn{7}{|l|}{ Kept awake by rash } \\
\hline Never & 53.4 & 60.1 & & 59.1 & 51.1 & \\
\hline$<1$ per week & 36.2 & 28.6 & & 29.4 & 29.6 & \\
\hline$>1$ per week & 10.3 & 11.3 & 0.479 & 11.5 & 19.3 & 0.005 \\
\hline
\end{tabular}

prevalence from $5.5 \%$ in $1967^{17}$ to $13.7 \%$ in $1987^{18}$ and $20.0 \%$ in 1994. ${ }^{10}$ Although the survey methodologies were different in these studies, this increase in prevalence was borne out by the high morbidity reflected in a report on healthcare utilisation in Singapore; In children up to 14 years of age, asthma ranked second highest among hospital discharge diagnoses, and it was the sixth commonest condition seen at the primary healthcare level in the late 1980s and early 1990s. ${ }^{19}$

In 1994, the prevalence of wheeze in the past 12 months in Singapore was intermediate in comparison with international data. ${ }^{9}$ It was anticipated that this would increase with rising affluence and urbanisation. ${ }^{20}$ Unexpectedly, we did not observe a consistent increase in prevalence of asthma symptoms. In fact, there was a decrease in most of the indices in the 6-7 year age group, except for the symptom of nocturnal cough. This result is in keeping with some recent studies, which suggest that the asthma burden may be plateauing. ${ }^{81}$ Reasons that have been suggested are an improvement in intervention and prevention efforts. Another possible reason is that the environmental factors that have resulted in this epidemic have "recruited" all genetically susceptible individuals and hence the prevalence of asthma has stabilised. ${ }^{7}$ The environmental factors that may predispose to asthma include pollution, microbial exposure, dietary change, decrease in childhood infections, and small family size. ${ }^{22}$ In this regard, exposure to passive smoke and animal allergens do not appear to be important factors in Singapore due to their low prevalence. ${ }^{23}$

The reason for the lack of substantial increase in asthma symptoms prevalence in Singapore may also be due to a combination of both improved diagnosis and management of asthma. Although not conclusive, this is suggested by the increase in doctor diagnosed asthma but decrease in 12 month asthma symptoms and severity.

The consistent increase in nocturnal cough in both age groups could possibly be related to an improved awareness of asthma symptoms. A recent ISAAC survey in Sheffield, England showed that the increase in 12 month symptoms of asthma was confined to mild symptoms. The authors also argued that improved therapy could have affected the severity profile of asthma symptoms, leading to an increase in the reporting of less severe symptoms. ${ }^{16}$

Eczema was the only allergic disorder with a consistent increase in symptom prevalence in both age groups. There was also a suggestion of increased severity of symptoms in the 12-15 year age group. Other studies have reported an increase in eczema prevalence, usually in parallel with increases in other atopic disease. ${ }^{15}$ This was also seen in a recent German report which also compared ISAAC phase one and three surveys. ${ }^{24}$ This has also been substantiated by a recent cross-sectional epidemiology study in Singapore where the one year prevalence of eczema was $20.8 \%{ }^{25}$ This study involved over 12000 (7, 12, and 16 year age groups) and the results were validated by cutaneous examination of all subjects. The prevalence data and the suggestion of increasing severity of eczema may necessitate the need for improved management of this disorder as we have seen with asthma. ${ }^{26}$ This observed digression in trends between asthma and eczema may also be explained by the suggestion that the genetic susceptibility to eczema may involve unique candidate genes which are not common with those for respiratory allergies. ${ }^{23}$

In conclusion, this comparative study of two ISAAC surveys has provided us with important information. It supports the notion that the "epidemic" of asthma may be beginning to plateau. Further work is necessary to verify that these results are at least in part due to the efforts put into improved diagnosis and management, as this would impact our management of other allergic diseases.

\section{Authors' affiliations}

S Y Chng, C P P Hia, N B H Ong, The Children's Medical Institute, National University Hospital, Singapore

X S Wang, T N Tan, L P C Shek, B W Lee, D Y T Goh, Department of Paediatrics, National University of Singapore

S Ma, Ministry of Health, Singapore 


\section{REFERENCES}

1 Burr ML, Butland BK, King S, et al. Changes in asthma prevalence: two surveys 15 years apart. Arch Dis Child 1989;64:1452-6.

2 Peat JK, van den Berg RH, Green WF, et al. Changing prevalence of asthma in Australian children. BMJ 1994;308:1591-6.

3 Shaw RA, Crane J, O'Donnell TV, et al. Increasing asthma prevalence in a rural New Zealand adolescent population: 1975-89. Arch Dis Child 1990;65:1319-23.

4 Nystad W, Magnus P, Gulsvik A, et al. Changing prevalence of asthma in school children: evidence for diagnostic changes in asthma in two surveys 13 yrs apart. Eur Respir J 1997; 10:1046-51.

5 Weitzman M, Gortmaker SL, Sobol AM, et al. Recent trends in the prevalence and severity of childhood asthma. JAMA 1992;268:2673-7.

6 D'Amato G, Liccardi G, D'Amato M, et al. Outdoor air pollution, climatic changes and allergic bronchial asthma. Eur Respir J 2002;20:763-76.

7 Ronchetti R, Villa MP, Barreto $M$, et al. Is the increase in childhood asthma coming to an end? Findings from three surveys of schoolchildren in Rome, Italy. Eur Respir J 2001;17:881-6.

8 Akinbami L, Schoendorf KC. Trends in childhood asthma: prevalence, health care utilization, and mortality. Pediatrics 2002;110:315-22.

9 Worldwide variation in prevalence of symptoms of asthma, allergic rhinoconjunctivitis, and atopic eczema: ISAAC. The International Study of Asthma and Allergies in Childhood (ISAAC) Steering Committee. Lancet 1998;351:1225-32.

10 Goh DY, Chew FT, Quek SC, et al. Prevalence and severity of asthma, rhinitis, and eczema in Singapore schoolchildren. Arch Dis Child 1996;74:131-5.

11 Holgate ST. The epidemic of allergy and asthma. Nature 1999;402:B2-4.

12 Sly RM. Changing prevalence of allergic rhinitis and asthma. Ann Allergy Asthma Immunol 1999;82:233-488, quiz 248-52.

13 Soto-Quiros ME, Soto-Martinez M, Hanson LA. Epidemiological studies of the very high prevalence of asthma and related symptoms among school children in Costa Rica from 1989 to 1998. Pediatr Allergy Immunol 2002;13:342-9.

14 Tanihara S, Nakamura Y, Oki I, et al. Trends in asthma morbidity and mortality in Japan between 1984 and 1996. J Epidemiol 2002;12:217-22.
15 Heinrich J, Hoelscher B, Frye C, et al. Trends in prevalence of atopic diseases and allergic sensitization in children in Eastern Germany. Eur Respir J 2002;19:1040-6

16 Ng Man Kwong G, Proctor A, Billings C, et al. Increasing prevalence of asthma diagnosis and symptoms in children is confined to mild symptoms. Thorax 2001;56:312-14.

17 Chong TM. Pattern of bronchial asthma in Singapore. Singapore Med J 1972;13:154-60.

18 Teo J, Quak SH, Low PS, et al. Childhood asthma in Singapore-changing trends. Proceedings of the 22nd Singapore Malaysia Congress of Medicine 1988:180.

19 Chew FT, Lee BW. Utilization of healthcare resources for asthma in Singapore: demographic features and trends. Asian Pac J Allergy Immunol 1998; 16:57-68

20 Aligne CA, Auinger P, Byrd RS, et al. Risk factors for pediatric asthma. Contributions of poverty, race, and urban residence. Am J Respir Crit Care Med 2000;162:873-7.

21 von Mutius E, Weiland SK, Fritzsch C, et al. Increasing prevalence of hay fever and atopy among children in Leipzig, East Germany. Lancet 1998;351:862-6.

22 Hopkin JM. Mechanisms of enhanced prevalence of asthma and atopy in developed countries. Curr Opin Immunol 1997;9:788-92.

23 Shek LP, Tay AH, Chew FT, et al. Genetic susceptibility to asthma and atopy among Chinese in Singapore-linkage to markers on chromosome 5q31-33. Allergy 2001;56:749-53.

24 Maziak W, Behrens T, Brasky TM, et al. Are asthma and allergies in children and adolescents increasing? Results from ISAAC phase I and phase III surveys in Munster, Germany. Allergy 2003;58:572-9.

25 Tay YK, Kong KH, Khoo L, et al. The prevalence and descriptive epidemiology of atopic dermatitis in Singapore school children. $\mathrm{Br} J$ Dermato 2002;146:101-6.

26 Tan CC. National disease management plans for key chronic noncommunicable diseases in Singapore. Ann Acad Med Singapore 2002;31:415-18.

\section{IMAGE IN PAEDIATRICS}

\section{Choroid plexus cyst: comparison of new ultrasound technique with old histological finding}

$\mathrm{n}$ histological examinations Shuanshoti and Netsky found choroid plexus cysts with multiple tubules lined by simple cuboidal epithelium in the wall. ${ }^{1}$ The proposed mechanism of formation of tubules and cysts was folding of the epithelium into the stroma to enlarge the surface of the choroid plexus. The epithelium can produce cerebrospinal fluid so that tubules and cysts can grow.

When we examined choroid plexus cysts of the lateral ventricle by means of a high resolution ultrasound system (HDI 5000 and 12-5 MHz-Linear-Broadband-Scanhead from Advanced Technology Laboratories, Washington, USA) we found spherical cysts with a double wall (fig 1).

We propose that the spherical form of the choroid plexus cyst is the result of secretion of cerebrospinal fluid by the epithelium into the cyst. The double wall seems to be the result of multiple tubules in the wall of the cyst which Shuanshoti and Nesky found in histological examinations of choroid plexus cysts in $1966 .^{1}$

A van Baalen, $\mathrm{H}$ Versmold Universitätsklinikum Benjamin Franklin, Hindenburgdamm 30, Berlin, Germany; van.baalen@medizin.fu-berlin.de doi: $10.1136 /$ adc. 2003.031245

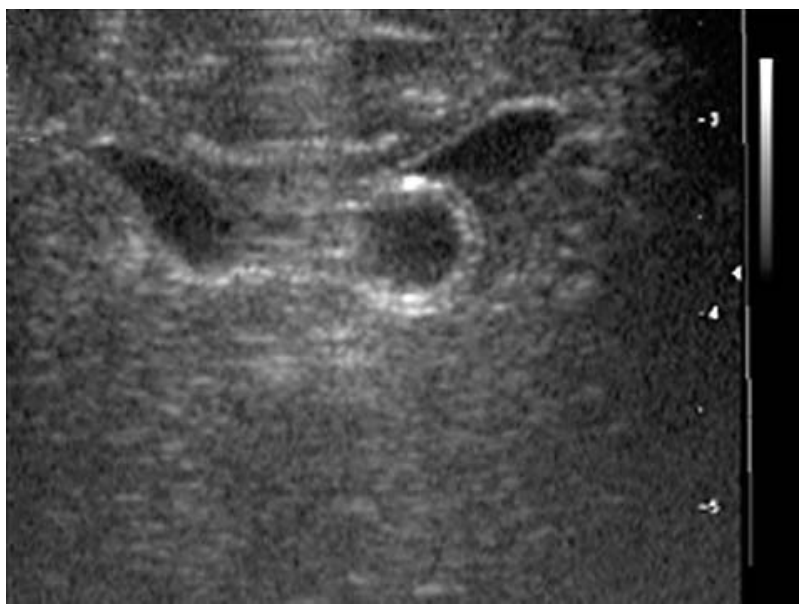

Figure 1 Coronal ultrasound section shows spherical cyst with double wall.

\section{Reference}

1 Shuangshoti S, Netsky MG. Neuroepithelial (colloid) cysts of the nervous system. Neurology 1966;16:887-903. 